\title{
Iodine status in UK schoolchildren
}

\author{
S. C. Bath ${ }^{1}$, E. Combet ${ }^{2}$, P. Scully ${ }^{1}$, M. Zimmermann ${ }^{3}$ and M. P. Rayman ${ }^{1}$ \\ ${ }^{1}$ University of Surrey, Guildford, Surrey, GU2 $7 \mathrm{XH},{ }^{2}$ University of Glasgow, Glasgow, G3 8SJ, UK and ${ }^{3}$ Swiss Federal \\ Institute of Technology, Zurich, Switzerland
}

Iodine is required for the production of thyroid hormones which are vital for brain development in pregnancy and childhood. Iodine status is low in some groups of the UK population, notably in teenage girls, women of childbearing age and in pregnant women ${ }^{(1)}$ and deficiency in UK pregnant women is associated with poorer cognitive scores in their children ${ }^{(2)}$. As there are no data on the iodine status of UK schoolchildren, we aimed to determine if iodine deficiency in the UK extends to school-age children whose brains are still developing.

A total of 134 schoolchildren (boys and girls aged 8-10 years) were recruited from three UK centres: Surrey (Guildford; $n=51$ ), Scotland (Glasgow, $n=53$ ) and Northern Ireland (Omagh; $n=30$ ) during the winter months (November 2012 to March 2013). The UK Reference Nutrient Intake for children aged 8-10 years is $110 \mu \mathrm{g} /$ day and the WHO criteria for adequate iodine status in schoolchildren is that the median urinary iodine concentration (UIC) should be $100-199 \mu \mathrm{g} / \mathrm{L}$ and that no more than $20 \%$ of the population should have a UIC below $50 \mu \mathrm{g} / \mathrm{L}^{(3)}$.

Based on the median UIC of $161.2 \mu \mathrm{g} / \mathrm{L}$ and the fact that just $4.4 \%(n=6)$ had a UIC below $50 \mu \mathrm{g} / \mathrm{L}$, the group was classified as having adequate iodine status. Though the median urinary iodine-to-creatinine ratio was lower than the UIC, at $157 \mu \mathrm{g} / \mathrm{g}$, the value was still indicative of an adequate iodine status in the group. There was a significant difference in UIC $(p=0.04)$ and iodine-to-creatinine ratio $(p=0.009)$ between UK centres; children in Northern Ireland had the highest UIC (see figure), whereas those in Scotland had a higher iodine-to-creatinine ratio than did Surrey children $(p=0.01)$.

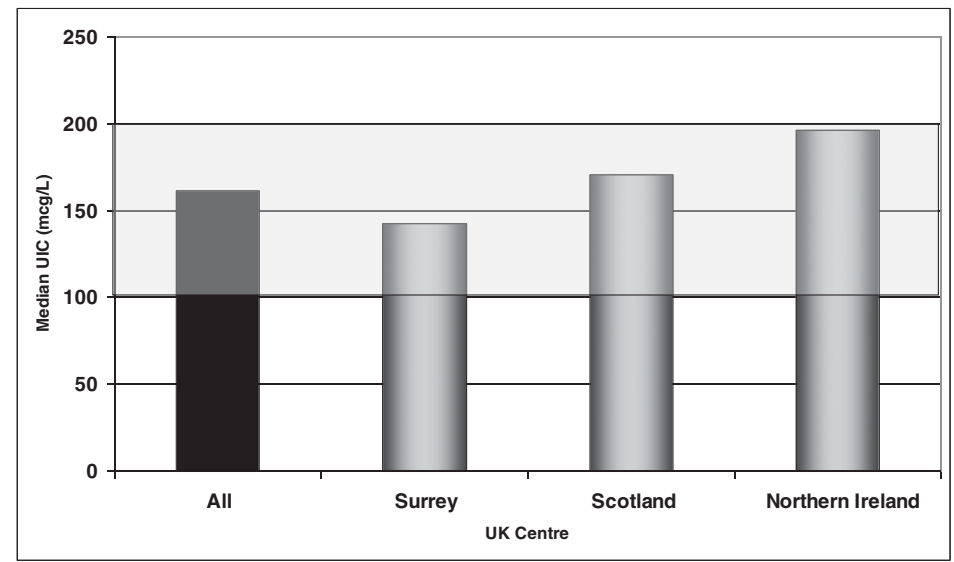

Figure. Urinary iodine concentration of UK schoolchildren (8-10 years). Shaded grey area shows the WHO adequate range for median urinary iodine concentration from a population of schoolchildren $(100-199 \mu \mathrm{g} / \mathrm{L})^{(3)}$.

These preliminary data suggest that iodine deficiency is unlikely to be a problem in 8-10 year old children in the UK. This could be a result of higher milk intake (the principal source of iodine in the UK diet) in this age group than in teenagers and adults. However these results should be interpreted with caution due to the limited sample size and the fact that the study was conducted during the winter months when the iodine concentration of milk is at its highest, hence this may be a best-case scenario. Further study in UK schoolchildren is required.

This work was supported by an MRC Population Health Scientist Fellowship for S.C. Bath.

1. Bath SC \& Rayman MP (2013) Proc Nutr Soc 72, 226-235.

2. Bath SC, Steer CD, Golding J et al. (2013) Lancet 382, 331-337.

3. WHO, UNICEF \& ICCIDD (2007). Geneva: World Health Organisation. 